\title{
Produção de fitomassa em genótipos de citros submetidos a estresse hídrico na formação do porta-enxerto
}

\author{
Janivan F. Suassuna ${ }^{1}$, Pedro D. Fernandes ${ }^{2}$, Ronaldo do $\mathrm{N}$ ascimento ${ }^{3}$, \\ Ana C. M. de Oliveira ${ }^{4}$, Kalyne S. A. de Brito $^{3} \&$ Alberto S. de Melo ${ }^{5}$
}

\begin{abstract}
RESU M 0
Devido à importância dos porta-enxertos no sucesso da citricultura e sua influência na tolerância a fatores de estresse, desenvolveu-se este estudo com o objetivo de avaliar a tolerância de porta-enxertos de citros ao estresse hídrico. Estudaram-se dois fatores: manejo hídrico ('sem estresse' e 'com estresse', neste último caso, com irrigação baseada em 50 e $25 \%$ da capacidade de campo) e porta-enxerto (10 genótipos de citros fornecidos pelo Programa de Melhoramento Genético de Citros da Embrapa M andioca e Fruticultura Tropical). Adotou-se o delineamento em blocos casualizados com três repetições e 15 plantas por parcela; avaliaram-se as fitomassas da parte aérea, das folhas, do caule, da raiz e total, além da relação raiz/parte aérea, razão de peso foliar e rendimento relativo. 0 déficit hídrico reduziu a fitomassa total e incrementou, em alguns porta-enxertos, a relação raiz/parte aérea. A fitomassa foliar é a variável mais afetada, negativamente, nos porta-enxertos de citros sob deficiência hídrica. 0 genótipo 'TSKFL x CTTR-017' possui capacidade de adaptação ao déficit hídrico, com potencial promissor para uso em áreas sujeitas às condições de seca.
\end{abstract}

Palavras-chave: Citrus spp, híbridos, deficiência hídrica, tolerância

\section{Dry matter production of citrus genotypes under water stress during the rootstock formation}

\begin{abstract}
Knowing the importance of the rootstocks for the success of the citrus crop and its influence on tolerance to stress factors, this study was conducted in order to evaluate tolerance of citrus rootstocks to water stress studying two factors: water management ('without stress' and 'under stress' and in this latter case, the irrigation was based on 50 and $25 \%$ moisture of field capacity) and rootstocks factor (10 citrus genotypes provided by Citrus Breeding Program of Embrapa Cassava and Tropical Fruits). A randomized block design was adopted with three replications and 15 plants per plot. Shoot, leaves, stem, root and total dry mass, root/shoot ratio, leaf weight ratio and relative yield were evaluated. W ater deficit reduced the total dry mass and increased the root/shoot ratio in some rootstocks. Leaf dry mass is the most sensible variable in citrus rootstocks under water deficit. 'TSKFL CTTR $x-017$ ' has a significant capacity of tolerance to drought, with promising potential for use in areas under drought conditions.
\end{abstract}

Key words: Citrus spp, hybrids, water deficit, tolerance

\footnotetext{
${ }^{1}$ D outorando em Engenharia Agrícola, UAEA/UFCG, Campus I, Av. Aprígio Veloso, 882, Bodocongó, CEP 58429-140, Campina Grande, PB. Fone: (83) 2101-1055, Ramal 24. E-mail: jf.su@hotmail.com

2 Pró-Reitoria de Pós-Graduação e Pesquisa, UEPB - Campus I, Rua das Baraúnas, 351, Bairro Universitário, CEP 58429-500, Campina Grande, PB. Fone: (83) 3344-5401. E-mail: pdantas@pq.cnpq.br

3 U AEA/UFCG - Campus I. Fone: (83) 2101-2885, Ramal 28. E-mail: ronaldo@deag.ufcg.edu.br; line.brito@hotmail.com

${ }^{4}$ FATEC, Rua Amália Xavier de Oliveira, S/N, Bairro Triangulo, CEP 63041-230, Juazeiro do Norte, CE. Fone: (88) 3566-4045, E-mail: ana_chris_br@hotmail.com

${ }^{5}$ Depto. de Biologia/U EPB - Campus I, Rua das Baraúnas, 351, Bairro U niversitário, CEP 58429-500, Campina Grande, PB. Fone: (83) $3344-5401$. E-mail: alberto@uepb.edu.br
} 


\section{INTRODUÇÃO}

O Brasil se destaca como maior produtor mundial de laranja (Citrus sinensis), com produção direcionada quase que totalmente para o mercado externo de suco concentrado e congelado de laranja. No entanto, são grandes a diversificação agroclimática do País e as condições particulares de cultivo, o que dificulta uma produção regular das frutas cítricas (Cerqueira et al., 2004).

No contexto da citricultura nacional, o Nordeste brasileiro tem se destacado como a segunda região maior produtora de citros do País, contribuindo com $10,06 \%$ da produção de laranja, 4,59\% da produção de tangerina (Citrus reticulata) e 13,17\% da produção de limão (Citrus limonia) (IBGE, 2010). Entretanto, no que se trata de região semiárida onde há maior possibilidade de ocorrência de estresse hídrico por falta de água, tem-se uma limitação à expressão da produtividade potencial das culturas agrícolas, visto ser a falta de água no solo limitante ao crescimento das espécies vegetais (Lechinoski et al., 2007).

Referente ao estresse hídrico, este pode ocorrer por excesso ou por deficiência de água; entretanto, o déficit hídrico é considerado, com frequência, o fator mais limitante ao crescimento e ao desenvolvimento das plantas, ocorrendo em grande extensão de área, sobretudo em regiões áridas e semiáridas, as quais se caracterizam pela baixa precipitação pluviométrica e pela irregularidade na distribuição das chuvas (Nogueira et al., 2001; Melo et al., 2010).

As plantas cítricas passam por períodos de estresse que diminuem e até paralisam seu crescimento (Mattos Júnior et al., 2005). Além disso, sua necessidade hídrica varia com a espécie, sistema de plantio, estádio de desenvolvimento, idade e condições climáticas, que afetam as características de absorção e o transporte de água na planta, movimento dos estômatos e transpiração (Mattos Júnior et al., 2005).

A citricultura nordestina está assentada, principalmente, no ecossistema de Tabuleiros Costeiros, fato que dificulta o aprofundamento do sistema radicular das plantas cítricas, tornando-as mais vulneráveis ao déficit hídrico (Peixoto et al., 2006). Por isso, é interessante, na citricultura desta região, a utilização de porta-enxertos com boas características de adaptação às condições climáticas, principalmente tolerantes à seca, que possuam diversidade de respostas à deficiência hídrica, fato que possibilitará a diversificação de materiais que sustentem a citricultura. Por outro lado, a seleção de materiais mais tolerantes, com capacidade de adaptação a estresses abióticos, permite alcançar-se rendimentos economicamente viáveis (Brito et al., 2008).

Alguns trabalhos (Cerqueira et al., 2004; Passos et al., 2006; Peixoto et al., 2006) relatam resultados de porta-enxertos cítricos sob déficit hídrico; entretanto, se restringem a períodos curtos de estresse e, mesmo assim, realizados em condições experimentais distintas, necessitando-se, ainda, de novos estudos, sobretudo para verificar os efeitos da deficiência hídrica contínua e progressiva, tal como ocorre em regiões citrícolas no Nordeste brasileiro.
O conhecimento da participação do ambiente na manifestação do fenótipo, também proporciona a otimização da seleção permitindo a escolha de genótipos superiores, sob qualquer condição (Marchioro et al., 2005). Bueno et al. (2006) relatam que, em diferentes tipos de ambiente, a seleção de genótipos bem adaptados e com alta produtividade, é um dos objetivos do melhoramento de plantas, mesmo que esta seleção possa ser prejudicada pela interação genótipo $\mathrm{x}$ ambiente, resultando em comportamento variável dos materiais cultivados.

Isto posto, o conhecimento das respostas de espécies cítricas à limitação hídrica, na fase de porta-enxertos, é indispensável por sua influência na tolerância da cultivar copa e, futuramente, no desenvolvimento e produção das plantas, a fim de fornecer subsídios ao cultivo em áreas com restrição de água. Objetivou-se, então, com este trabalho, avaliar, por meio da produção de fitomassa, a tolerância de genótipos de citros ao estresse hídrico, na fase de formação do porta-enxerto.

\section{Material e MÉTODOS}

O trabalho foi desenvolvido em ambiente protegido, no período compreendido entre março e outubro de 2009, nas instalações da Unidade Acadêmica de Engenharia Agrícola, Centro de Tecnologia e Recursos Naturais da Universidade Federal de Campina Grande (UFCG) em Campina Grande, PB, nas coordenadas geográficas $7^{\circ} 15$ ' $18^{\prime}$ ' de latitude $S$ e $35^{\circ} 52^{\prime}$ 28 " de longitude $\mathrm{W}$, a uma altitude de $550 \mathrm{~m}$.

Os fatores estudados foram manejo hídrico $(\mathrm{MH})$ e portaenxertos (PE) compondo um fatorial 2 x 10 (2 manejos hídricos x 10 genótipos) os quais, ao serem combinados, resultaram em 20 tratamentos. Os manejos hídricos foram: $\mathrm{MH}_{1}$ - umidade no substrato dos recipientes, correspondente ao nível de $100 \%$ do conteúdo hídrico próximo à capacidade de campo (CC) durante todo o transcorrer do experimento e $\mathrm{MH}_{2}$ - umidade no substrato dos recipientes, correspondente ao nível de 50\% da CC de 60 a 135 dias após a semeadura (DAS), intensificandose o nível de estresse para $25 \%$ da CC a partir de 136 DAS, estendendo-se até 210 DAS, com duração de 75 dias cada nível de estresse.

$\mathrm{O}$ fator PE foi constituído de 10 genótipos de porta-enxertos de citros (variedades e híbridos) (Tabela 1) fornecidos pelo Programa de Melhoramento Genético de Citros - PMG Citros, da Embrapa Mandioca e Fruticultura Tropical, Cruz das Almas, BA

O delineamento experimental adotado foi em blocos casualizados, com três repetições, e a parcela foi composta de 15 plantas úteis de cada genótipo, nas unidades experimentais.

Utilizaram-se, para o cultivo dos porta-enxertos, recipientes (tubetes) com capacidade volumétrica de $288 \mathrm{~mL}$, os quais foram preenchidos com substrato, composto de uma parte de solo de textura média e outra parte de substrato comercial (1:1) à base de casca de pinus, vermiculita e húmus, cujas caracterís-ticas físico-químicas foram as seguintes:

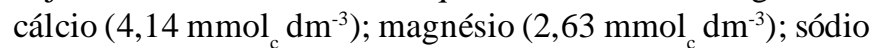
$\left(2,56 \mathrm{mmol}_{\mathrm{c}} \mathrm{dm}^{-3}\right)$; potássio $\left(0,14 \mathrm{mmol}_{\mathrm{c}} \mathrm{dm}^{-3}\right)$; hidrogênio $(2,11$ $\left.\mathrm{mmol}_{\mathrm{c}} \mathrm{dm}^{-3}\right)$; alumínio $\left(0,00 \mathrm{mmol}_{\mathrm{c}} \mathrm{dm}^{-3}\right)$; carbonato de cálcio 
Tabela 1. Relação dos genótipos (variedades e híbridos) de porta-enxertos de citros, selecionados pelo Programa de M elhoramento G enético de Citros da Embrapa M andioca e Fruticultura Tropical - PM G Citros, submetidos ao estresse hídrico

\begin{tabular}{|c|c|}
\hline Ordem & Porta-enxertos (abreviaturas e nomes) \\
\hline 1 & LCRSC - Limoeiro 'Cravo Santa Cruz' (Citrus limonia L. Osbeck) \\
\hline 2 & $\begin{array}{l}\text { TSKC \{Tangerineira 'Sunki' [C. sunki (Hayata) hort. ex Tanaka] seleção comum\} x TRENG- } 256 \text { \{Trifoliata [P. trifoliata (L.) Raf.] 'English' - } \\
256\}\end{array}$ \\
\hline 3 & TSKC x \{TR [Trifoliata (Poncirus trifoliata (L.) Raf.] x LCR [Limoeiro 'Cravo' (C. limonia Osbeck)]\} - 059 \\
\hline 4 & $\begin{array}{l}\text { TSKFL }\{\text { Tangerineira 'Sunki' [C. sunki (Hayata) hort. ex Tanaka] seleção 'da Flórida'\} x CTC25 \{Citrange [C. sinensis x P. trifoliata (L.) Raf.] } \\
\text { C25\} - } 010\end{array}$ \\
\hline 5 & $\begin{array}{l}\text { TSKFL x CTTR \{Tangerineira 'Sunki' [C. sunki (Hayata) hort. ex Tanaka] seleção 'da Flórida'\} x \{Citrange [C. sinensis x P. trifoliata (L.) Raf.] } \\
\text { 'Troyer'\} - } 017\end{array}$ \\
\hline 6 & $\begin{array}{l}\text { TSKC \{Tangerineira 'Sunki' [C. sunki (Hayata) hort. ex Tanaka] seleção comum\} x TRENG- } 256 \text { \{Trifoliata [P. trifoliata (L.) Raf.] 'English' - } \\
264\}\end{array}$ \\
\hline 7 & CTSW [Citrumelo (C. paradisi Macfad x P. trifoliata) 'Swingle'] \\
\hline 8 & LCRC - Limoeiro 'Cravo' (C. limonia Osbeck) \\
\hline 9 & $\begin{array}{l}\text { TSKFL \{Tangerineira 'Sunki' [C. sunki (Hayata) hort. ex Tanaka] seleção 'da Flórida'\} x LRM [Limoeiro 'Rugoso Mozael' (C. jambhiri Lush.) } \\
\text { seleção de 'Mozael'] - } 007\end{array}$ \\
\hline 10 & LVK - Limoeiro 'Volkameriano' (C. volkameriana V. Tem. \& Pasq.) \\
\hline
\end{tabular}

qualitativo: ausência; carbono orgânico: 0,64\%; matéria orgânica: $1,10 \%$; nitrogênio: 4,86\%; fósforo assimilável determinado pelo método de Mehlich-1(6,84 mg $\left.100 \mathrm{~g}^{-1}\right) ; \mathrm{pH}$ $\mathrm{H}_{2} \mathrm{O}(1: 2,5): 6,84$; condutividade elétrica - suspensão soloágua: $1,55 \mathrm{mS} \mathrm{cm}^{-1}$.

Com a umidade do substrato próximo à capacidade de campo, foram postas a germinar três sementes por recipiente e, após uniformização da germinação, procedeu-se ao desbaste das plântulas deixando-se apenas a de maior vigor, eliminandose as demais. No período correspondente à germinação e ao crescimento inicial das plântulas (até 60 DAS), as irrigações foram feitas de modo igual em todas elas, duas vezes ao dia, utilizando-se de um regador de forma a manter a umidade do solo próximo à capacidade de campo.

Após 60 dias da semeadura (DAS), a irrigação nos tratamentos sem estresse hídrico $\left(\mathrm{MH}_{1}\right)$ foi realizada com uso de Becker, aplicando-se um volume único às plantas de todos os genótipos, em função da evapotranspiração média obtida por pesagem, de maneira a serem mantidos próximos à capacidade de campo; já no tratamento de estresse hídrico $\left(\mathrm{MH}_{2}\right)$, o volume de água aplicado (Va) por planta foi determinado diariamente, por gravimetria, conforme a Eq. (1). Quando se intensificou o estresse, o Va passou a ser determinado de acordo com a Eq. (2). As plantas eram irrigadas quando a umidade no substrato se encontrava abaixo de 50 e $25 \%$ do conteúdo hídrico correspondente ao da capacidade de campo, em cada caso, respectivamente, nas duas etapas de aplicação de estresse. Para tanto e no mesmo horário, os recipientes com as respectivas plantas foram pesados diariamente, para verificação da quantidade de água consumida e, posteriormente, adicionados os volumes necessários a manter a capacidade hídrica determinada para cada tratamento.

$$
\begin{aligned}
& \mathrm{Va}=\mathrm{PM} 50 \% \mathrm{CC}-\mathrm{Pa} \\
& \mathrm{Va}=\mathrm{Pm} 25 \% \mathrm{CC}-\mathrm{Pa}
\end{aligned}
$$

em que:

Va - volume de água a ser aplicado, $\mathrm{mL}$

$\mathrm{Pa}$ - peso atual dos recipientes, $\mathrm{g}$
Pm50\%CC - peso médio do recipiente com 50\% do teor de umidade em $\mathrm{CC}, \mathrm{g}$

Pm25\%CC - peso médio do recipiente com $25 \%$ do teor de umidade em $\mathrm{CC}, \mathrm{g}$

Para se estimar o teor de água correspondente ao da umidade em capacidade de campo no substrato foram amostrados, aleatoriamente, cinco recipientes contendo substrato, obtendose o peso do conjunto recipiente + substrato seco, após secagem ao ar livre; isto feito, os mesmos foram postos em um recipiente com água para saturação, aguardando-se o tempo necessário para a água chegar até a superfície do substrato, por ascensão capilar, momento em que foram retirados e, depois de cessado o escoamento por drenagem natural, quantificouse o peso do conjunto recipiente + substrato úmido. Pela diferença entre as duas pesagens obteve-se, então, o conteúdo hídrico retido pelo substrato, correspondente ao da capacidade de campo, utilizado no manejo das irrigações para estimativa dos níveis de estresse hídrico aplicados.

Foram feitas fertilizações de cobertura, semanalmente, com nitrogênio, fósforo, potássio e micronutrientes, aplicando-se $10 \mathrm{~mL}$ por planta, da solução de $10 \mathrm{~g}$ de fosfato monoamônico (MAP) $+5 \mathrm{~g}$ de nitrato de potássio $+1 \mathrm{~g}$ do produto comercial Albatrós (N-P-K-Mg: 7-17-35-3 + micronutrientes, por cada litro de água) de acordo com recomendação de adubação para citros, em formação de mudas (Rontondano \& Melo, 2009).

No final do experimento (210 DAS) realizou-se a coleta das plantas, separando-as em partes (raízes, caules e folhas), as quais foram acondicionadas em sacos de papel perfurados e colocadas em estufa a $65^{\circ} \mathrm{C}$, para secagem até peso constante; em seguida, procedeu-se à pesagem desse material obtendose os valores expressos em grama (g), para as fitomassas da raiz (FSR), do caule (FSC), da folha (FSF), da parte aérea (FSPA) (caules e folhas), cujo somatório com a FSR resultou na fitomassa total (FST). A razão de peso foliar (RPF) foi obtida dividindo-se a fitomassa das folhas (FSF) pela fitomassa total (FST) produzida em cada planta (Benincasa, 2003). Fez-se, ainda, o estudo do particionamento de fitomassa das plantas nos diferentes órgãos, analisando-se a percentagem de fitomassa formada em folhas, caules e raízes, separadamente. 
Adotou-se, para avaliação dos genótipos quanto à tolerância ao estresse hídrico, o critério do rendimento relativo classificando-os em diferentes graus de tolerância com base na redução de fitomassa total, adaptando-se o procedimento encontrado em Fageria \& Gheyi (1997) para rendimento de cultura, quanto a tolerância à salinidade.

Os dados obtidos foram submetidos à análise de variância e ao teste 'F' até 5\% de probabilidade de erro (Ferreira, 2008). Para se avaliar o efeito comparativo do estresse hídrico entre os genótipos procedeu-se à análise por aglutinação de médias (Scott \& Knott, 1974).

\section{RESULTADOS E DISCUSSÃO}

Os fatores manejo hídrico $(\mathrm{MH})$ e porta-enxerto $(\mathrm{PE})$ foram significativamente diferentes $(\mathrm{p}<0,05)$, nas variáveis de fitomassa do caule (g), das folhas (g), da parte aérea (g) e total $(\mathrm{g})$, assim como, entre a relação raiz/parte aérea e a razão de peso foliar. Da mesma forma, efeito significativo na interação MH x PE também foi identificado, evidenciando ter havido dependência entre fatores nos efeitos sobre essas variáveis e que os efeitos do estresse hídrico ocorreram de forma distinta, entre os dez genótipos estudados, fato interessante quando se tenta selecionar materiais tolerantes (Tabela 2).

$\mathrm{Na}$ fitomassa da raiz (FSR) (g), observada na Figura 1A, o estresse hídrico determinou aumento na sua produção, exceto nos genótipos 'TSKFL x CTTR-017', 'CTSW' e 'TSKFL x LRM -007'. No restante dos porta-enxertos, houve aumento da FSR em resposta ao déficit hídrico; apesar de os genótipos 'LCRSC', 'TSKFL x CTC25 - 010' e 'LCRC' aumentarem a FSR sob estresse, não diferiram estatisticamente nas duas condições hídricas. Acrescente-se, no entanto, que o confinamento das raízes dentro dos recipientes pode ter contribuído para esses resultados, não permitindo haver distinção neste atributo devido aos tratamentos. Redução mais acentuada (62,49\%) na FSR foi constatada no híbrido 'TSKFL x LRM-007', em situação de estresse hídrico; o genótipo que expressou maior FSR sob estresse foi o 'TSKC x TRENG - 256'.

Apresentaram maior fitomassa no sistema radicular, sob estresse hídrico, os genótipos 'LCRSC', 'TSKC x TRENG-256' e 'LVK' e foi menor oFSR no 'TSKFL x LRM-007', sob estresse hídrico, conforme se observa na Figura 1A. Magalhães Filho et al. (2008) observaram semelhança na fitomassa das raízes do

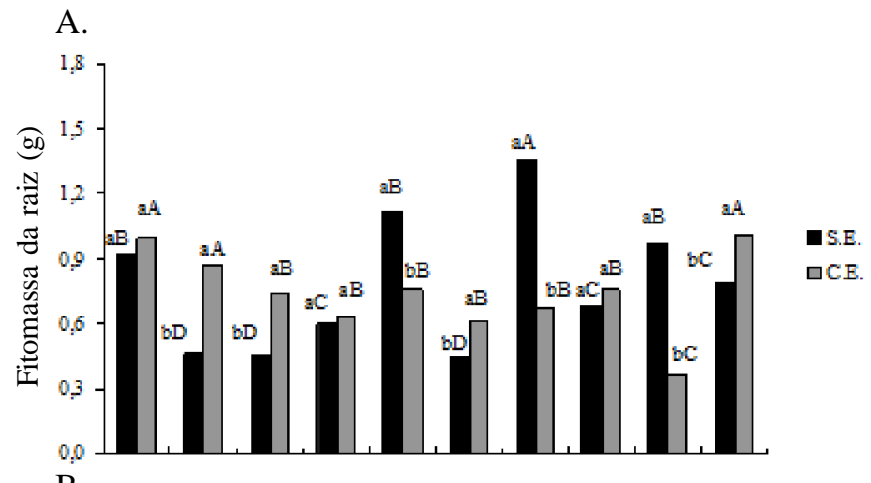

B.
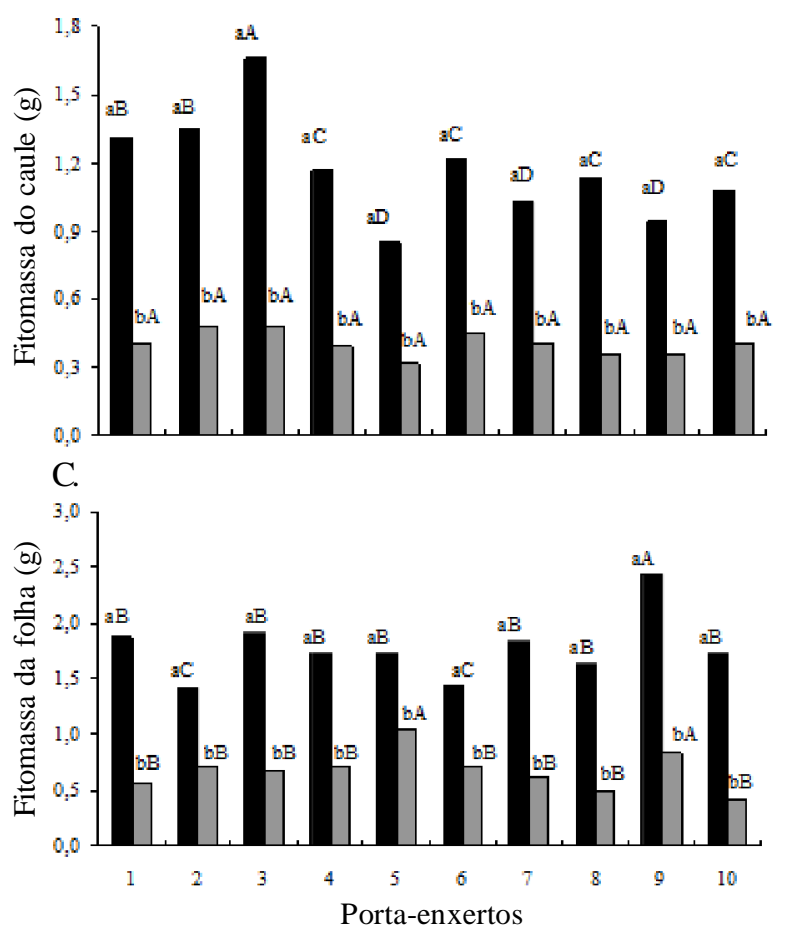

Obs.: S.E. - sem estresse e C.E. - com estresse

Porta-enxerto com mesma letra minúscula não sofreu efeito significativo do manejo hídrico pelo teste ' $F$ ' $(p<0,05)$; porta-enxertos com mesma letra maiúscula pertencem ao mesmo grupo dentro de cada manejo hídrico, pelo tes te de Scott-Knott $(p<0,05)$

Figura 1. Fitomassa da raiz (FSR) (A), fitomassa do caule (FSC) (B) e fitomassa da folha (FSF) (C) em porta-enxertos de citros sob dois manejos hídricos

porta-enxerto limoeiro 'Cravo', com e sem deficiência hídrica; todavia, o porta-enxerto 'trifoliata' teve menor fitomassa no sistema radicular, sob deficiência hídrica; esses autores

Tabela 2. Resumo da análise de variância para as fitomassas de raízes (FSR) (g), caules (FSC) (g), folhas (FSF) (g), parte aérea (FSPA) (g) e total (FST) (g), relação raiz/parte aérea (R/PA) e razão de peso foliar (RPF) em porta-enxertos de citros (PE) sob dois manejos hídricos $(\mathrm{MH})$

\begin{tabular}{|c|c|c|c|c|c|c|c|c|}
\hline \multirow{2}{*}{ FV } & \multirow{2}{*}{ GL } & \multicolumn{7}{|c|}{ Quadrados médios } \\
\hline & & FSR & FSC & FSF & FSPA & FST & R/PA & RPF \\
\hline PE & 9 & $0,1408^{* *}$ & $0,1141^{* *}$ & $0,2173^{* *}$ & $0,2120^{* *}$ & $0,2312^{* *}$ & $0,1187^{* *}$ & $0,0236^{* *}$ \\
\hline $\mathrm{MH}$ & 1 & $0,0114^{\text {ns }}$ & $8,8169^{* *}$ & $19,3541^{* *}$ & $54,2971^{* *}$ & $55,8839^{* *}$ & $3,5253^{* *}$ & $0,2037^{* *}$ \\
\hline PE $\times$ MH & (9) & $0,2650^{* *}$ & $0,0545^{* *}$ & $0,1275^{* *}$ & $0,1905^{* *}$ & $0,3924^{* *}$ & $0,1615^{* *}$ & $0,0125^{* *}$ \\
\hline BLOCO & 2 & $0,01123^{*}$ & $0,00170^{\text {ns }}$ & $0,0169^{\text {ns }}$ & $0,0230^{\text {ns }}$ & $0,0569^{\text {ns }}$ & $0,0044^{\mathrm{ns}}$ & $0,00044^{\mathrm{ns}}$ \\
\hline ERRO & 38 & 0,0159 & 0,0073 & 0,0224 & 0,0216 & 0,0507 & 0,0124 & 0,0024 \\
\hline CV $(\%)$ & & 16,49 & 10,85 & 12,25 & 7,30 & 8,10 & 21,94 & 11,75 \\
\hline Média & & 0,76 & 0,79 & 1,22 & 2,01 & 2,77 & 0,50 & 0,41 \\
\hline
\end{tabular}

ns - não significativo; * significativo a 0.05 de probabilidade $e^{* *}$ significativo a 0,01 de probabilidade pelo teste ' $\mathrm{F}$ ' 
observaram, ainda, que, excetuando-se a fitomassa das raízes do 'Cravo', em todos os outros órgãos, o acúmulo de fitomassa foi menor devido ao déficit hídrico. Conforme resultados apresentados neste estudo, o porta-enxerto limoeiro 'Cravo' aumentou a produção de fitomassa na raiz, fato que, possivelmente, está condicionado às suas características genéticas, com possibilidade de ser este um indicativo promissor de crescimento sob condições hídricas desfavoráveis.

Pelos dados expostos na Figura 1B pode-se notar, também, redução expressiva da fitomassa do caule, quando as plantas estavam sob os efeitos do estresse hídrico, fato registrado em todas as variedades e híbridos estudados. Essas reduções variaram de 50\% no 'CTSW' a 71\% no 'TSKC x (TR x LCR)059'. Referente à influência dos genótipos nesta variável, percebeu-se, na condição de estresse hídrico, que os valores de FSC se mantiveram semelhantes entre os porta-enxertos, com respostas também semelhantes.

Conforme se observou no sistema radicular e nos caules, também, ocorreu redução significativa no acúmulo de fitomassa nas folhas (g) no tratamento em que as plantas foram submetidas a estresse hídrico por deficiência de água (Figura 1C). Dentre os 10 porta-enxertos, o híbrido 'TSKC x CTTR 017 ' foi menos sensível, com menor redução $(39,88 \%)$ da FSF, em razão da restrição hídrica submetida, tendo novamente bom indicativo de tolerância ao estresse hídrico.

Nesta avaliação se identificaram, sob estresse hídrico, apenas dois grupos de porta-enxertos para a FSF $(\mathrm{g})$, em que o 'TSKFL x LRM-007' manteve sua classificação no grupo de maior FSF, juntamente com o 'TSKFL x CTTR- 017', que apresentaram 0,82 e 1,04 g planta $^{-1}$ de FSF; no restante dos materiais genéticos de citros estudados ('LCRSC', 'TSKC $\mathrm{x}$ TRENG-256', 'TSKC x (TR x LCR)-059', 'TSKFL x CTC25 010', 'TSKC x TRENG-264', 'CTSW', 'LCRC' e 'LVK') foram identificados os valores menos expressivos nesta variável, com a menor média de $0,41 \mathrm{~g}_{\text {planta }}{ }^{-1}$ no ' $L V K$ ' e a maior média de 0,71 g planta ${ }^{-1}$, obtida no híbrido 'TSKFL x CTC25-010'. Neste componente se registraram diminuições acentuadas em função do estresse $(70,74 ; 50,70 ; 65,46 ; 60,11 ; 39,88 ; 51,04 ; 67,02 ; 69,87$; 66,25 e $76,57 \%$, respectivamente). Conforme os resultados apresentados, o estresse hídrico parece ter afetado, negativamente, a alocação de fitomassa em todos os órgãos, na fase inicial dos porta-enxertos de citros, sobretudo nas folhas. Tais resultados embasam a informação de que um incremento menor de fitomassa foliar se reflete em diminuição da capacidade fotossintética da planta, resultando em menor acúmulo de fotoassimilados. Em condições de estresse hídrico, o maior acúmulo de fitomassa da folha e do caule é fator importante, haja vista que este incremento de carboidratos e energia será disponibilizado para o desenvolvimento da cultura (Caixeta et al., 2010).

De maneira semelhante, na fitomassa da parte aérea (FSPA) (g) também houve efeito expressivo do estresse hídrico, em todos os genótipos de citros (Figura 2A), de vez que foram notadas, anteriormente, reduções nas fitomassas de caules e folhas; na parte aérea, a formação de fitomassa foi reduzida pronunciadamente quando os genótipos foram submetidos a estresse hídrico, registrando-se decréscimos da ordem de 70,05; 57,$37 ; 68,14 ; 62,28 ; 47,15 ; 63,68 ; 64,42 ; 69,32 ; 64,96$ e $71,13 \%$ em relação às plantas bem hidratadas (SE), nos genótipos 'LCRSC', 'TSKC x TRENG-256', 'TSKC x (TR x LCR)-059', 'TSKFL x CTC25-010', 'TSKFL x CTTR-017', 'TSKC x TRENG-264', 'CTSW', 'LCRC', 'TSKFL x LRM-007' e 'LVK', respectivamente. Destaque-se, neste aspecto, a superioridade do 'TSKFL x CTTR- 017' e do 'TSKC x TRENG-256' que sofreram menor efeito sobre a parte aérea nas plantas condicionadas ao déficit hídrico contínuo, evidenciado pelas menores reduções nesta variável (Figura 2A). A observação desses atributos sugere melhor capacidade de adaptação ao estresse, nesses porta-enxertos, considerando-se a observação deste comportamento, também, nas outras características avaliadas. Redução em matéria seca total e, por conseguinte, da parte aérea também foi relatada por Peixoto et al. (2006), ao estudarem o efeito do estresse hídrico em genótipos de citros.
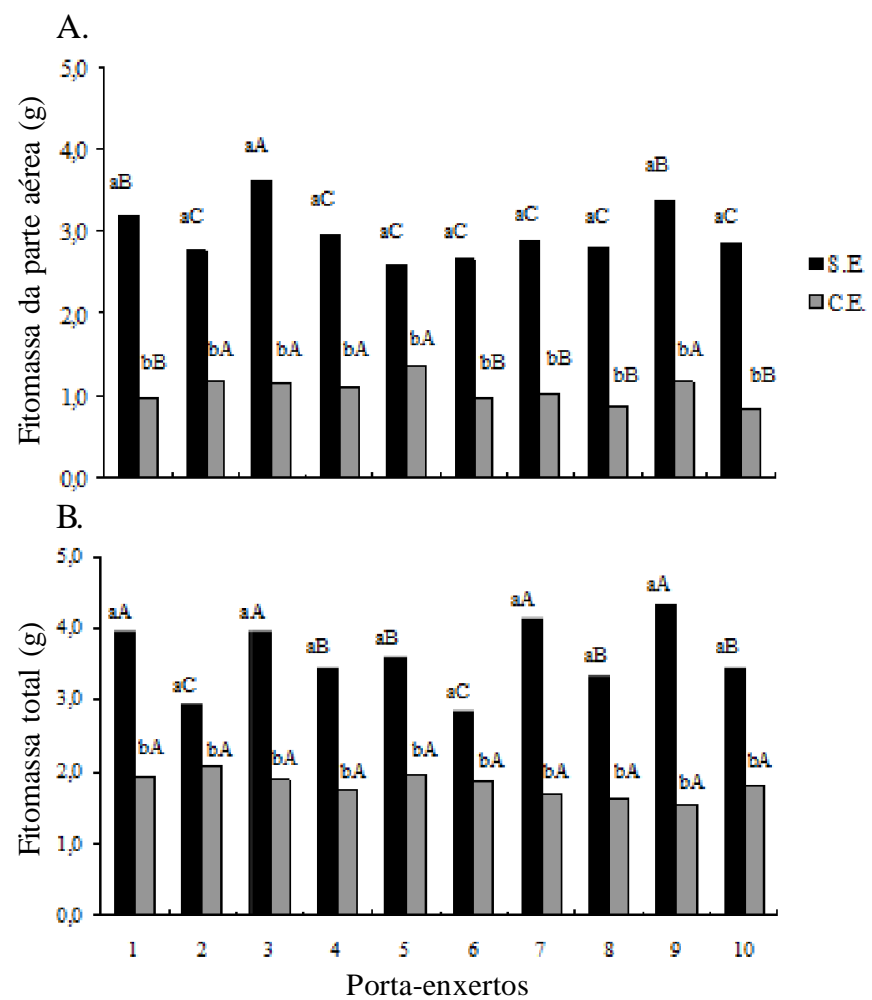

Obs.: S.E. - sem estresse e C.E. - com estresse

Porta-enxerto com mesma letra minúscula não sofreu efeito significativo do manejo hídrico pelo teste ' $F$ ' $(p<0,05)$; porta-enxertos com mesma letra maiúscula pertencem ao mesmo grupo dentro de cada manejo hídrico, pelo teste de Scott-Knott $(p<0,05)$

Figura 2. Fitomassa da parte aérea (FSPA) (A) e fitomassa total (FST) (B) em porta-enxertos de citros sob dois manejos hídricos

Sob estresse hídrico (50\% e depois $25 \%$ da CC), registraramse duas classes de porta-enxertos: com maior FSPA ('TSKC $\mathrm{x}$ TRENG-256', 'TSKC x (TR x LCR)-059', 'TSKFL x CTC25 010', 'TSKFL x CTTR-017' e 'TSKFL x LRM-007') que formaram entre 1,11 e 1,36 $\mathrm{g} \mathrm{planta}^{-1}$ de fitomassa na parte aérea, e desempenho inferior foi constatado nos genótipos 'LCRSC'; 'TSKC x TRENG-264' 'CTSW'; 'LCRC' e 'LVK', com produção de FSPA entre 0,86 e 1,02 g planta $^{-1}$.

Tal efeito sobre a parte aérea foi observado em citros por Magalhães Filho et al. (2008), que também evidenciaram diminuição da parte aérea em plantas de 'Cravo' e de 
'Trifoliata', com indicação da existência de um mecanismo de adaptação à seca que priorizou o crescimento das raízes, sob estresse hídrico. Os autores associam esta resposta ao mecanismo de defesa contra o déficit hídrico, visto que, sob tal condição, as plantas investem em mais biomassa para o sistema radicular objetivando aumentar a capacidade de absorção de água e nutrientes.

Constatou-se, corroborando com os resultados anteriores, maior formação de fitomassa total nos porta-enxertos cultivados sem estresse hídrico (Figura 2B), quando então se identificou diferença significativa entre as médias dos tratamentos hídricos sem estresse (SE) e com estresse (CE). Na fitomassa total (g) percebe-se, para a fonte de variação genótipo, distinção entre os porta-enxertos, apenas na condição de cultivo sem estresse, constatando-se resposta semelhante nos materiais, dentro da condição de estresse hídrico. Mesmo não havendo diferença significativa na formação de fitomassa nos porta-enxertos, dentro do tratamento hídrico com estresse, os genótipos 'LCRC' e 'TSKFL x LRM-007' tiveram produções de FST inferiores às dos demais genótipos (1,61 e 1,64 $\mathrm{g} \mathrm{planta}^{-1}$, respectivamente).

Indicaram menores reduções na FST (g) em função do déficit hídrico, os genótipos 'TSKC x TRENG-256', 'TSKFL x CTTR017' e 'TSKC x TRENG - 264', os quais já apresentaram boas características adaptativas ao estresse, considerando os resultados obtidos nas variáveis antecedentes.

É provável que este comportamento se relacione com as características genéticas intrínsecas desses genótipos, já que os três são híbridos derivados do 'Trifoliata'. Magalhães Filho et al. (2008) registraram, estudando duas combinações copa/ porta-enxerto de citros sob déficit hídrico (laranjeira 'Valência' sobre 'Cravo' e sobre 'Trifoliata'), redução na fitomassa total e nos diferentes órgãos das plantas. É oportuno observar que, mesmo se considerando as alterações morfofisiológicas, como meios de evitar os efeitos negativos da deficiência hídrica, as plantas têm decréscimos significativos na fitomassa (Machado et al., 2009), porém, neste estudo as plantas sofreram, embora com menor intensidade, os efeitos do estresse.

Quanto à relação raiz/parte aérea (R/PA), percebe-se que o déficit hídrico não elevou esta relação nos genótipos 'TSKFL x CTTR-017' e 'TSKFL x LRM-007', visto que não sofreram variação significativa, em razão do estresse, ao mesmo tempo em que se constatou aumento entre 60 e $80 \%$ da R/PA, na maioria dos genótipos, sob déficit hídrico (Figura 3A). Sob restrição hídrica, o porta-enxerto com maior R/PA foi o limoeiro 'Volkameriano' ('LVK'); já os menores valores da R/PA foram constatados em 'TSKFL x CTC25 -010', 'TSKFL x CTTR-017' e 'TSKFL x LRM-007'; valores de R/PA, maiores que 1,0, foram detectados nos genótipos 'LCRSC' $(1,05)$ e 'LVK' $(1,22)$, confirmando maior crescimento das raízes, em detrimento da parte aérea. Esta arquitetura radicular, relacionada provavelmente à melhor exploração de áreas úmidas, aliada à maior relação entre a raiz e a parte aérea, pode ser importante mecanismo de escape à deficiência hídrica.

Pereira et al. (2003) julgam importante avaliar o crescimento do sistema radicular e da parte aérea, com base no acúmulo de matéria seca e do incremento da área foliar, em porta-enxertos cítricos. Além disto, é notório que os índices determinados na

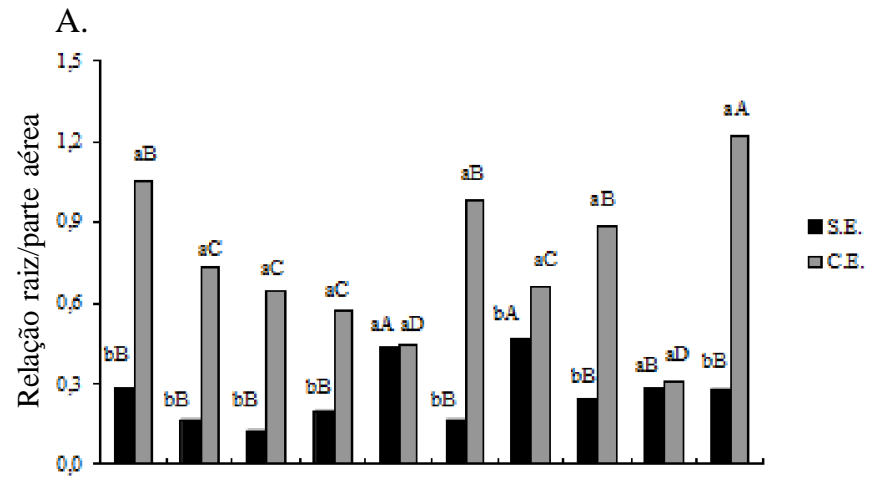

B.

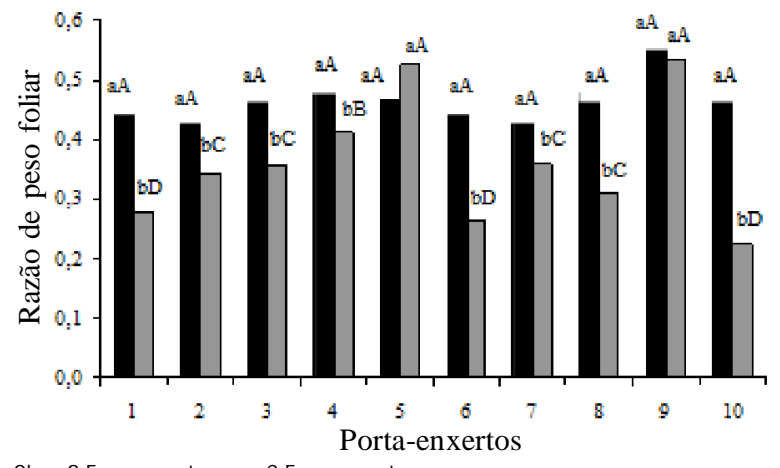

Obs.: S.E. - sem estresse e C.E. - com estresse

Porta-enxerto com mesma letra minúscula não sofreu efeito significativo do manejo hídrico pelo teste ' $F$ ' $(p<0,05)$; porta-enxertos com mesma letra maiúscula pertencem ao mesmo grupo dentro de cada manejo hídrico, pelo teste de Scott-Knott $(p<0,05)$

Figura 3. Relação raiz/parte aérea (R/PA) (A) e razão de peso foliar (RPF) (B) em porta-enxertos de citros sob dois manejos hídricos

análise de crescimento indicam a capacidade do sistema assimilatório das plantas em sintetizar (fonte) e alocar a matéria orgânica nos diversos órgãos (drenos) que dependem da fotossíntese, respiração e translocação de fotoassimilados dos sítios de fixação de carbono, aos locais de utilização ou de armazenamento, onde ocorrem o crescimento e a diferenciação dos órgãos (Fontes et al., 2005).

Tal como neste trabalho, aumento da R/PA foi verificado por Figueirôa et al. (2004) que, estudando estresse hídrico em aroeira, evidenciaram maior alocação de biomassa para a raiz, em plantas sob $25 \%$ da umidade de $\mathrm{CC}$, em relação aos tratamentos de 75 e $50 \%$ da umidade de CC, o que aumenta a R/ PA.

A razão de peso foliar (RPF), cujos dados são apresentados na Figura 3B, é definida pela relação entre fitomassa das folhas e a unidade de fitomassa da planta inteira representando, ainda, a capacidade de translocação de fotoassimilados da parte aérea para o resto da planta e, quanto maior for esta razão, mais eficiente será a translocação (Scalon et al., 2006). Verificou-se, portanto, que este índice foi influenciado pela redução da umidade do substrato, ocorrendo diminuição na RPF das plantas que sofreram estresse hídrico; referido comportamento foi diferente no híbrido 'TSKFK x CTTR-0,17', no qual a RPF foi superior quando sob estresse hídrico, porém, esta variação ocorreu em nível não significativo; no genótipo 'TSKFL x LRM-007' a redução na RPF foi menos pronunciada, não se encontrando diferença significativa $(\mathrm{p}<0,05)$ entre os manejos hídricos (Figura 3B). 
Nos materiais 'TSKFK x CTTR - 0,17' e 'TSKFL x LRM-007' notaram-se, sob estresse hídrico, as maiores médias para esta razão, sendo menor a RPF nos porta-enxertos 'LCRSC', 'TSKC x TRENG - 264'e 'LVK' (Figura 3B). A RPF representa o quanto a planta investiu da sua produção, via fotossíntese, para as folhas (Oliveira et al., 2002; Brant et al., 2009). Uma baixa RPF indica que mais massa foi distribuída para o caule e as raízes do que para os órgãos fotossintéticos, o que pode ser vantajoso para as plantas, de vez que mais massa seca é alocada para as raízes, permitindo maior absorção de água e nutrientes (Silva et al., 2006). Considerando o relatado neste parágrafo, os genótipos 'TSKFK x CTTR-0,17' e 'TSKFL x LRM-007' tiveram uma translocação de fotoassimilados mais eficiente, mesmo sob déficit hídrico, resultado este fundamentado nos dados obtidos na produção de fitomassa foliar (Figura 1C), em que esses híbridos tiveram maior FSF, na condição de estresse hídrico.

Os dados da Figura 4 complementam o estudo da produção de matéria seca nos porta-enxertos, podendo-se constatar aumento na alocação de fitomassa radicular, entre os genótipos expostos a estresse, e sua redução nos caules e folhas, sendo essas alterações morfológicas resultantes da baixa disponibilidade hídrica; entretanto, nos híbridos 'TSKFK x CTTR-0,17' e 'TSKFL x LRM-007', este mecanismo não ocorreu, evidenciando-se maior alocação de fitomassa para a formação e crescimento de folhas e caules, mesmo sob estresse. É provável que esses porta-enxertos não tenham sofrido severamente os efeitos negativos do estresse, não necessitando desenvolver tal estratégia.

A razão do maior direcionamento de fitomassa para a parte radicular nos porta-enxertos de citros é considerada característica adaptativa das plantas submetidas a ambientes

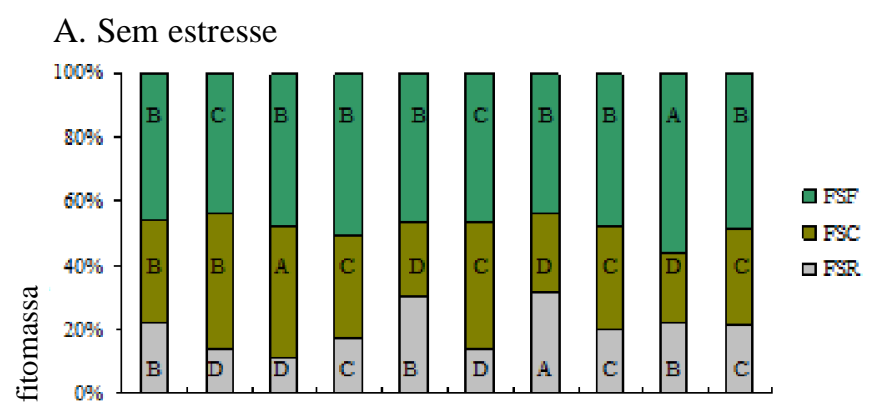

B. Com estresse

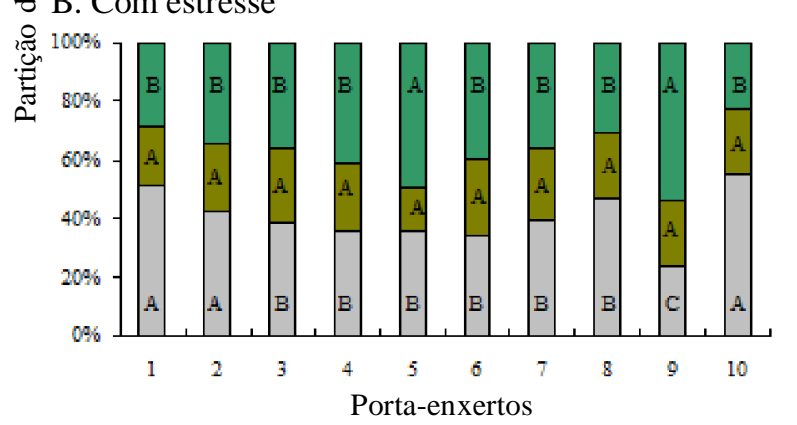

Fitomassa folha - FSF, Fitomassa caule - FSC, Fitomassa raízes - FSR

Porta-enxertos com mesma letra pertencem ao mesmo grupo, conforme teste de Scott-Knott $(p<0,05)$

Figura 4. Partição de fitomassa nas plantas sem estresse (A) e com estresse (B), em porta-enxertos de citros sob dois manejos hídricos sujeitos a períodos de seca prolongados. Isto prioriza a absorção de água e, também, resulta em menor perda por transpiração foliar, visto que a alocação de massa para as folhas é diminuída. Guimarães et al. (2011) explicam que a primeira reação das plantas, ao serem submetidas à deficiência hídrica, é reduzir o potencial osmótico e, consequentemente, hídrico das raízes, no intuito de gerar um gradiente de potencial capaz de promover a absorção de água, a partir do solo, ou reduzir a transpiração, de tal maneira que a planta mantenha um balanço positivo de água.

Comumente, também se explica que o ajuste osmótico nas folhas ocorre mais lentamente, levando à diminuição ou à parada da extensão das paredes celulares e ao menor crescimento da parte aérea. Assim, quando o potencial da água é reduzido nas raízes verifica-se, em várias espécies, um rápido ajuste osmótico, auxiliando o restabelecimento da pressão de turgor e permitindo a manutenção do alongamento celular (Hsiao \& Xu, 2000).

Na classificação dos porta-enxertos, quanto à tolerância ao estresse hídrico, pelo critério do rendimento relativo por base na redução de fitomassa total (\%), os genótipos foram classificados em moderadamente tolerantes (MT), moderadamente sensíveis (MS) e sensíveis (S), conforme a Tabela 3. Foram classificados moderadamente tolerantes os híbridos 'TSKC $\mathrm{x}$ TRENG-256' e 'TSKFL x CTTR-017'; foram moderadamente sensíveis os genótipos 'LCRSC', 'TSKC x (TR x LCR)-059', 'TSKFK x CTTR-010', 'TSKC x TRENG-264', 'CTSW', 'LCRC' o genótipo 'LVK' foi classificado sensível. Este critério de classificação foi adaptado da classificação proposta por Fageria \& Gheyi (1997) para rendimento de culturas sob salinidade.

Tabela 3. Classificação quanto à tolerância, baseada no rendimento relativo (\%), pela redução da fitomassa total, em genótipos de porta-enxertos de citros, sob estresse hídrico

\begin{tabular}{|c|c|c|c|}
\hline Porta-enxertos ${ }^{*}$ & $\begin{array}{l}\text { Rendimento } \\
\text { relativo (\%) }\end{array}$ & Faixa & Classificação\# \\
\hline 01 & 52,66 & $40-60$ & MS \\
\hline 02 & 36,33 & $20-40$ & MT \\
\hline 03 & 53,66 & $40-60$ & MS \\
\hline 04 & 51,00 & $40-60$ & MS \\
\hline 05 & 40,00 & $20-40$ & MT \\
\hline 06 & 53,66 & $40-60$ & MS \\
\hline 07 & 50,00 & $40-60$ & MS \\
\hline 08 & 46,33 & $40-60$ & MS \\
\hline 09 & 59,66 & $40-60$ & MS \\
\hline 10 & 64,00 & $>60$ & $S$ \\
\hline
\end{tabular}

Evidencia-se, novamente, com base nesses resultados, o bom desempenho do 'TSKFL x CTTR-017', destacado em todas as variáveis analisadas neste estudo, fato que confirma seu potencial para uso como porta-enxerto em áreas sujeitas à seca. Dentre as principais características deste porta-enxerto se destaca seu pequeno porte, um fator inerente aos cruzamentos originados do Poncirus trifoliata, que auxilia na capacidade de tolerância aos estresses abióticos e tem qualidade horticultural reconhecida pela indução de frutos de qualidade 
superior, às copas de diversas variedades cítricas; além disto, os híbridos de 'trifoliata' são os citros mais adaptados às condições subtropicais ou temperadas, razão pela qual são mais indicados para condições tropicais (Passos et al., 2006). Capacidades de adaptação ao estresse hídrico e salino já foram observadas neste porta-enxerto, por Cerqueira et al. (2004) e Brito (2010), respectivamente.

\section{CONClusõEs}

1. O déficit hídrico reduz a formação de fitomassa em genótipos de citros na fase de formação do porta-enxerto.

2. Nas plantas sob estresse hídrico, a fitomassa da parte aérea é reduzida e a fitomassa da raiz é incrementada em alguns porta-enxertos, aumentando a relação R/PA.

3. Com base no rendimento relativo de fitomassa total, os genótipos de citros estudados são classificados, quanto à tolerância ao estresse hídrico, em: Moderadamente Tolerantes (MT): 'TSKC x TRENG - 256' e 'TSKFL x CTTR-017'; Moderadamente Sensíveis (MS): 'LCRSC', 'TSKC x (TR x LCR)059', 'TSKFL x CTC25-010', 'TSKC x TRENG-264', 'CTSW', 'LCRC' e 'TSKFL x LRM - 007' e Sensíveis (S): 'LVK'.

4. A fitomassa foliar é a variável mais afetada negativamente nos porta-enxertos de citros, sob deficiência hídrica.

5. O genótipo 'TSKFL x CTTR-017' possui expressiva capacidade de adaptação ao déficit hídrico, com potencial promissor para uso em áreas sujeitas às condições de seca.

\section{LITERATURA CITADA}

Benincasa, M. M. P. Análise de crescimento de plantas (noções básicas). 2.ed, Jaboticabal: FUNEP, 2003. 41p.

Brant, R. da S.; Pinto, J. E. B.; Rosa, L. F.; Albuquerque, C. J. B.; Ferri, P. H.; Corrêa, R. M. Crescimento, teor e composição do óleo essencial de melissa cultivada sob malhas fotoconversoras. Ciência Rural, v.39, p.1401-1407, 2009.

Brito, M. E. B. Tolerância de genótipos de citros ao estresse salino. Campina Grande: UFCG, 2010. 155p. Tese Doutorado

Brito, M. E. B.; Fernandes, P. D.; Gheyi, H. R.; Melo, A. S. de; Cardoso, J. A. F.; Soares Filho, W. S. Sensibilidade de variedades e híbridos de citrange à salinidade na formação de porta-enxertos. Revista Brasileira de Ciências Agrárias, v.3, p 343-353, 2008.

Bueno, L. C. S.; Mendes, A. N. G.; Carvalho, S. P. Melhoramento genético de plantas: Princípios e procedimentos. 2.ed., Lavras: UFLA, 2006. 282p.

Caixeta, D. F.; Fagan, E. B.; Silva, C. P. L.; Martins, K. V.; Alves, V.A. B.; Silva, R. B.; Gonçalves, L. A. Crescimento da plântula de milho à aplicação de inseticidas na semente sob diferentes disponibilidades hídricas. Revista da FZVA, v.17, p.78-87, 2010.

Cerqueira, E. C.; Castro Neto, M. T.; Peixoto, C. P.; Soares Filho, W. S.; Ledo, C. A. S.; Oliveira, J. G. Resposta de porta-enxertos de citros ao déficit hídrico. Revista Brasileira de Fruticultura, v.26, p.515-519, 2004.
Fageria, N. K.; Gheyi, H. R. Melhoramento genético das culturas e seleção de cultivares. In: Gheyi, H. R.; Queiroz, J. E.; Medeiros, J. F.de (ed.) Manejo e controle da salinidade na agricultura. Campina Grande: UFPB/SBEA, 1997. p.363-383.

Ferreira, D. F. SISVAR: Um programa para análise de ensino de estatística. Revista Científica Symposium, v.6, p.36-41, 2008.

Figueirôa, J. M.; Barbosa, D. C. A.; Simabukuro, E. A. Crescimento de plantas jovens de Miracrodruon urundeuva Allemão (Anacardiaceae) sob diferentes regimes hídricos. Acta Botânica Brasilica, v.18, p.573-580, 2004.

Fontes, P. C. R.; Dias, E. N.; Silva, D. J. H. Dinâmica do crescimento, distribuição de matéria seca na planta e produção de pimentão em ambiente protegido. Horticultura Brasileira, v.23, p.94-99, 2005.

Guimarães, C. M.; Stone, L. F.; Oliveira, J. P.; Rangel, P. H. N.; Rodrigues, C. A. P. Sistema radicular do arroz de terras altas sob deficiência hídrica. Pesquisa Agropecuária Tropical, v.41, p.126-134, 2011.

Hsiao, T. C.; Xu, L. K. Sensitivity of growth of roots versus leaves to water stress: biophysical analysis and relation to water transport. Journal of Experimental Botany, v.51, p.1595$1616,2000$.

IBGE - Instituto Brasileiro de Geografia e Estatística. Produção agrícola municipal 2010. <http://www.ibge.gov.br>. 10 Nov. 2010.

Lechinoski, A. L.; Freitas, J. M. N.; Castro, D. S.; Lobato, A. K. da S.; Oliveira Neto, C. F.; Cunha, R. L. M.; Costa, R. C. L. Influência do estresse hídrico nos teores de proteínas e aminoácidos solúveis totais em folhas de Teca (Tectona grandis L. f.). Revista Brasileira de Biociências, v.5, p.927-929, 2007.

Machado, R. S.; Ribeiro, R. V.; Marchiori, P. E. R.; Machado, D. F. S. P.; Machado, E. C.; Landell, M. G. A. Respostas biométricas e fisiológicas ao déficit hídrico em cana-de-açúcar, em diferentes fases fenológicas. Pesquisa Agropecuária Brasileira, v.44, p.1575-1582, 2009.

Magalhães Filho, J. R.; Amaral, L. R.; Machado, D. F. S. P.; Medina, C. L.; Machado, E. C. Deficiência hídrica, trocas gasosas e crescimento de raízes em laranjeira 'Valência' sobre dois tipos de porta-enxerto. Bragantia, v.67, p.75-82, 2008.

Marchioro, V. S.; Carvalho, F. I . F. de, Oliveira, A. C. de; Lorencetti, C.; Benin, G.; Silva, J. A. G. da; Hartwig, I; Shimidt, D.; Cargnin, A.; Simioni, D. Métodos de semeadura na condução de populações segregantes de aveia e suas interações com o ambiente de seleção, Ciência Rural, v.35, p.290-294, 2005.

Mattos Júnior, D.; Negri, J. D.; Pio, R. M.; Pompeu Júnior, J. Citros C498. Campinas: Instituto Agronômico e FUNDAG, 2005. 929p.

Melo, A. S.; Suassuna, J. F.; Fernandes, P. D.; Brito, M. E. B.; Suassuna, A. F.; Netto, A. O. A. Crescimento vegetativo, resistência estomática, eficiência fotossintética e rendimento do fruto da melancieira em diferentes níveis de água. Acta Scientiarum. Agronomy, v.32, p.73-79, 2010.

Nogueira, R. J. M. C.; Moraes, J. A. P. V.; Burity, H. A. Alterações na resistência à difusão de vapor das folhas e relações hídricas em aceroleira submetidas a déficit de água. Revista Brasileira de Fisiologia Vegetal, v.13, p.75-87, 2001. 
Oliveira, M. A. J.; Bovi, M. L. A.; Machado, E. C.; Gomes, M. M. A.; Habermann, G.; Rodrigues, J. D. Fotossíntese, condutância estomática e transpiração em pupunheira sob deficiência hídrica. Scientia Agricola, v.59, p.59-63, 2002.

Passos, O. S.; Peixoto, L. S.; Santos, L. C.; Caldas, R. C.; Soares Filho, W. S. Caracterização de híbridos de Poncirus trifoliata e de outros porta-enxertos de citros no Estado da Bahia. Revista Brasileira de Fruticultura, v.28, p.410-413, 2006.

Peixoto, C. P.; Cerqueira, E. C.; Soares Filho, W. S.; Castro Neto, M. T.; Ledo, C. A. S.; Matos, F. S.; Oliveira, J. G. Análise de crescimento de diferentes genótipos de citros cultivados sob déficit hídrico. Revista Brasileira de Fruticultura, v.28, p.439-443, 2006.

Pereira, W. E.; Siqueira, D. L. de; Puiatti, M. Growth of citrus rootstocks under aluminium stress in hydroponics. Scientia Agricola, v.60, p.31-41, 2003.
Rotondano, A. K. F.; Melo, B. Citros. Universidade Federal de Uberlândia, <http://www.fruticultura.iciag.ufu.br/ aduba5.html>. 21 Mar. 2009.

Scalon, S. P. Q.; Mussury, R. M.; Scalon Filho, H.; Francelino, C. S. F. Desenvolvimento de mudas de aroeira (Schinus terebinthifolius) e sombreiro (Clitoria fairchildiana) sob condições de sombreamento. Ciência e Agrotecnologia, v.30, p.166-169, 2006.

Scott, A.; Knott, M. A cluster analysis method for grouping means in the analysis of variance. Biometrics, v.30, p.507$12,1974$.

Silva, M. L. S.; Viana, A. E. S.; São José, A. R.; Amaral, C. L. F.; Matsumoto, S. N.; E Pelacani, C. R. Desenvolvimento de mudas de maracujazeiro (Passiflora edulis Sims f. flavicarpa Deg.) sob diferentes níveis de sombreamento. Acta Scientarum. Agronomy, v.28, p.513-521, 2006. 